\title{
Is International Travel an Emerging Issue on Transmission of Beijing Lineage Mycobacterium tuberculosis?
}

\author{
Pavithra S. Madamarandawala, ${ }^{1}$ Srinath Satyanarayana, ${ }^{2,3}$ Collins Timire,, \\ Aashifa Yaqoob, ${ }^{5}$ Dushantha Madegedara $\mathbb{D}^{6},{ }^{6}$ and Dhammika N. Magana-Arachchi $\mathbb{D}^{1}$ \\ ${ }^{1}$ National Institute of Fundamental Studies, Kandy, Hantana Road, Sri Lanka \\ ${ }^{2}$ International Union Against Tuberculosis and Lung Disease (The Union), Paris, France \\ ${ }^{3}$ The Union, South-East Asia Office, New Delhi, India \\ ${ }^{4}$ Ministry of Health and Child Care-National Tuberculosis Control Programme, Harare, Zimbabwe \\ ${ }^{5}$ Common Management Unit (AIDS, TB \& Malaria), Ministry of National Health Services, Regulations and Coordination, \\ Islamabad, Pakistan \\ ${ }^{6}$ Respiratory Disease Treatment Unit, General Teaching Hospital, Kandy, Sri Lanka
}

Correspondence should be addressed to Dhammika N. Magana-Arachchi; dhammika.ma@nifs.ac.lk

Received 29 December 2019; Accepted 19 May 2020; Published 28 August 2020

Academic Editor: Jean-Paul J. Gonzalez

Copyright (c) 2020 Pavithra S. Madamarandawala et al. This is an open access article distributed under the Creative Commons Attribution License, which permits unrestricted use, distribution, and reproduction in any medium, provided the original work is properly cited.

\begin{abstract}
Mycobacterium tuberculosis belonging to Beijing sublineage (BL) is associated with high tuberculosis (TB) transmission, multidrug resistance, and adverse treatment outcomes. Sri Lanka experiences an increase in the number of travellers/workers to and from high TB-burden countries, and there is risk of getting BL strains imported into the country. In this context, a cohort study was conducted to assess the prevalence of BL strains among pulmonary tuberculosis (PTB) patients in the Kandy district of Sri Lanka (a popular tourist destination) and its association with patients' sociodemographic and clinical characteristics. The study population included sputum smear-positive PTB patients diagnosed from February 2018-July 2019. Fresh sputum samples were collected for culturing and conducted polymerase chain reaction using BL-specific primers. Among the 101 patients recruited, presence of BL strains could be ascertained in 94 patients of which 24 (26\%; $95 \%$ CI: $18 \%-35 \%)$ had BL strains. Prevalence of BL strains was higher among those with high sputum smear grades $(2+$ and $3+)(P<0.05)$ and those who had travelled abroad $(P<0.05)$. The prevalence was also higher among young people (aged $<35$ years). Treatment success rates were similar in patients with $(83 \%)$ and without BL strains $(83 \%$ vs. $81 \%$; $P$ value $=0.8375)$. The prevalence of BL strains in Kandy, Sri Lanka, was high compared to previously reported figures in Sri Lanka, and the percentage drives closer to the countries in South East Asia. International travel raises itself as an emerging issue in BL transmission urging the need of policies and practices in immigration/ emigration strategies. The study findings have the potential to alter the TB epidemiology in the country and might represent the situation in other underexplored countries as well. Therefore, it is important to monitor the trends and factors related to the prevalence of Beijing strains globally and make decisions as a whole.
\end{abstract}

\section{Introduction}

Seven lineages of Mycobacterium tuberculosis (MTB), the bacteria that causes "Tuberculosis" (TB), have been identified till date [1]. Of these, East Asian lineage is inevitably the most widespread, and Beijing sublineage (BL) is its major component [2]. BL was first reported in Beijing, China, in
1995, and shortly, it was spotted/reported in other countries as well [3].

BL gained attention in 1990s due to its links to drug resistance, being "escape variants" of Bacille Calmette-Guerin (BCG) vaccination, higher transmission, and predilection for outbreaks (New York (1990s) and Canaria Island (1993)) [2, 4, 5]. However, studies after 2000s have not 
shown clear global patterns on these concerns as expected. For instance, while many studies observed the association of $\mathrm{BL}$ with multidrug resistant TB (MDR-TB-resistance to at least isoniazid and rifampin) as in Indonesia, Iran, Pakistan, and Georgia, some studies showed no such association $[4,6,7]$. Given this uncertainty, the current global concern is to assess the BL prevalence, study its associations with patient's characteristics, assess the timely changes, and make informed decisions [8].

Sri Lanka, a developing country in South Asia, has a moderate TB burden (estimated incidence rate $(2017)=64$ / 100,000 population) [7]. In $2003,8.8 \%$ of the TB patients tested belonged to BL [9]. However, this study was conducted among a group of Sri Lankans who travelled abroad and may not be a good representative. During 2005-2006, 14.3\% BL prevalence was reported from Colombo, Sri Lanka, and in Kandy, Sri Lanka, it was $22.4 \%$ in 2012 [10, 11]. After the end of the 30-year civil war in 2009 and attaining politicoeconomic stability, the country experienced an increase in the number of travellers/workers to and from high TB-burden countries for tourism and construction workforce. Sri Lanka's TB incidence rate has been stable for the last decade [12]. However, there are concerns that highly virulent $\mathrm{BL}$ strains may get imported from the neighboring countries as was seen in Canaria Islands [5]. Therefore, there is a need to assess the current BL prevalence and monitor its trends in various geographic settings of the country [11]. In this context, we undertook a study in Kandy (a popular tourist destination) with the aim of understanding the prevalence, patient characteristics, and treatment outcomes associated with BL strains among tuberculosis patients in Kandy, Sri Lanka.

\section{Materials and Methods}

2.1. Ethics. Approval was obtained from the Ethics Advisory Group, International Union against Tuberculosis and Lung Disease (19/19) and Ethical Review Committee, General Teaching Hospital, Kandy (GTHK), Sri Lanka. Data were collected after obtaining written informed consent from each patient.

2.2. Study Design. We conducted a cohort study involving both primary and secondary data collection.

\subsection{Study Setting}

2.3.1. General Setting. The study was conducted in Kandy, the capital district in the central province, Sri Lanka (Figure 1). It is the second most important district in the country with a total population of $\sim 1.4$ million and a daily transient population of $\sim 100,000$ people to the city [13].

2.3.2. Hospital Setting. GTHK is a tertiary care government hospital which has a separate chest clinic where all the TB patients diagnosed in Kandy district are registered. There are two consultant respiratory physicians (CRPs) who hold clinics on alternate days. They enroll all PTB

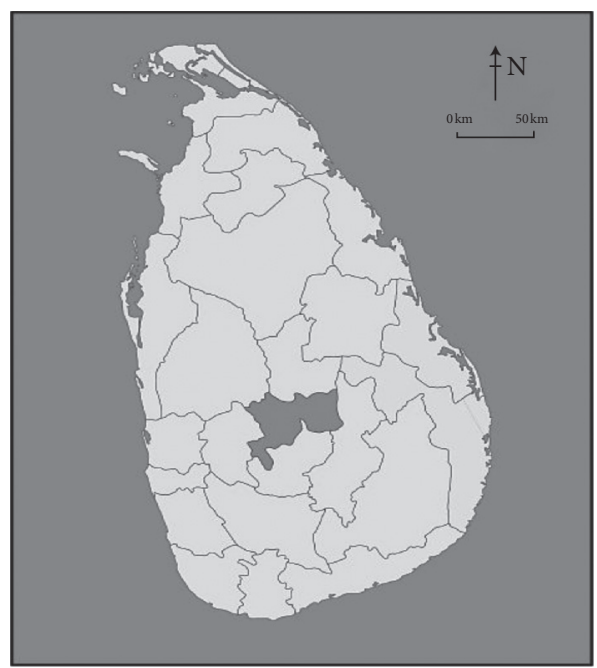

Figure 1: A map of Sri Lanka depicting the study area: Kandy district.

patients diagnosed both in the hospital and district clinics outside the hospital, under their care. Both physicians receive approximately similar patients in terms of numbers and patient characteristics. Sputum microscopy and, depending on the physician's decision, culture, and Xpert MTB/Rif assay are conducted for TB diagnosis. All sputum smear-positive patients are registered and initiated on a six-month treatment regimen. Suspected MDR-TB patients are transferred to the national hospital for respiratory diseases. There is directly observed treatment, and a treatment booklet is maintained for each patient. Treatment adherence is monitored ensuring that patients attend their scheduled follow-up hospital visits. At the end of treatment, all TB patients are categorized into standard TB treatment outcomes as per the World Health Organization (WHO) guidelines (see Table S1 in Supplementary Materials for treatment outcome definitions for TB patients) [14].

2.4. Study Population. The study population included all sputum smear-positive PTB patients diagnosed at GTHK, Sri Lanka, from February 2018 to July $2019(n=101)$. Due to operational and administrative reasons, we had permission to recruit patients enrolled into care by one of the two CRPs.

2.5. Sputum Sample Collection and Processing. Fresh sputa were collected from each patient and decontaminated using the modified Petroff's method [15]. The resultant pellet was used to inoculate Lowenstein-Jensen (LJ) media, containing thiophene-2-carboxylic acid hydrazide (TCH) and paranitrobenzoic acid (PNB) to differentiate MTB and nontuberculous mycobacteria. The media were incubated at $37^{\circ} \mathrm{C}$ and $28^{\circ} \mathrm{C}$ in light and dark conditions, and growth was observed for 4-8 weeks. Acid-fast staining was performed on the culture isolates, and those which gave positive results were suspected to be MTB. 
2.6. Molecular Testing. Deoxyribonucleic acid (DNA) was extracted from suspected MTB isolates using the standard CTAB (N-cetyl-N,N,N-trimethylammonium bromide) method and from culture-negative sputa using modified Booms' method $[16,17]$. DNA was amplified in a multiplex polymerase chain reaction (PCR) using a real-time instrument (RotorGeneQ, Germany). Primers used were specific for the Rv0627c gene of MTB complex which possesses a single-nucleotide polymorphism, cytosine to guanine at position 426, unique to BL (Box 1) [18]. The standard strain, $\mathrm{H} 37 \mathrm{Rv}$, and a confirmed Beijing strain were used as the nonBeijing and Beijing controls. Amplicons were run on a $2 \%$ agarose gel incorporated with ethidium bromide and visualized using a gel documentation system (Syngene, UK). BL strains were identified by the two distinct bands (261 bp and $163 \mathrm{bp}$ ) that travel the same distance as the base pairs in the positive control. DNA that did not show either of the two bands in multiplex PCR was PCR-amplified conventionally using primers Pt8 and Pt9 which partially amplifies IS6110, an insertion element unique to MTB complex (Box 1) [19].

2.7. Data Variables, Sources, and Data Collection. Sociodemographic, socioeconomic, behavioural, and clinical information was collected using an interviewer-administered questionnaire. Data on treatment outcomes, sputum grading, and MTB lineage were collected from treatment booklets and laboratory registers. The key outcome variable was MTB lineage (Beijing/non-Beijing lineage).

2.8. Data Analysis. Data were double-entered, validated using EpiData v3.1, and were analyzed using EpiData v2.2.2.183 (EpiData Association, Odense, Denmark). Frequencies were calculated for categorical variables disaggregated by Beijing/non-Beijing status. Continuous variables were summarized using means and standard deviation. Chi-square test was used to assess the differences in the proportions. Prevalence ratio and its 95\% confidence intervals (CIs) were calculated to assess the association between BL infection and sociodemographic and clinical factors. Level of significance was set at $P<0.05$.

\section{Results}

In total, 101 sputum smear-positive PTB patients were recruited, and 76 patients' (75\%) sputa yielded acid-fast stain positive cultures on TCH-LJ (Figure 2). Out of 76, Beijing/ non-Beijing status could not be ascertained in two isolates as they did not produce amplicon/s in multiplex PCR. However, they were confirmed as MTB upon conventional PCR (Figure 3$)$. Among the culture-negative group $(n=25)$, five were excluded from further analysis due to insufficient DNA quantity. Overall, BL status could be ascertained in 94 samples, out of which 24 (26\%; 95\% CI: 19\%-35\%) had BL strains (7 (35\%) from culture-negative sputa and 17 (23\%) from culture-positive isolates; prevalence ratio in culturenegative : culture-positive samples $=1.52 \quad(95 \% \mathrm{CI}$ : $0.74-3.16))$.
The demographic, socioeconomic, behavioural characteristics, and the $\mathrm{BL}$ prevalence among various patient groups are summarized in Table 1. Overall, the mean age (standard deviation) was 44 (16) years, and majority $66 \%$ were males. On bivariable analysis, the relative prevalence of BL strains was higher among those who had travelled abroad, young people, females, those with higher educational grades, those whose profession was business, and in those without history of alcohol or smoking. However, except travel history $(P=0.0117)$, these associations were not statistically significant (Table 2 ).

Table 3 summarizes the patients' clinical characteristics disaggregated by the $\mathrm{BL}$ status. $67 \%$ of patients with $\mathrm{BL}$ strains had high sputum grades (Chi-square $P$ val$\mathrm{ue}=0.0441)$. In addition, other clinical characteristics were similar in all patients of the 94 patients, and treatment outcomes were available for 64 patients by the end of September 2019. All were treated with first-line anti-TB drug regimen, and their treatment outcomes are summarized in Table 4 . The treatment success rate was similar in all patients.

\section{Discussion}

The study had four important findings. Approximately, 26\% of PTB patients in Kandy were infected with BL strains. BLinfected patients have higher sputum smear grade, and a majority have an out-of-country travel history, and among all, the treatment outcomes were similar.

First, the prevalence of BL strains among PTB patients was higher compared to the previous figures in Sri Lanka $[9,10]$. This could be due to an increasing trend within Kandy. However, it is not clear whether this represents variations in the $\mathrm{BL}$ distribution in our country, as there are no studies reported from regions other than Colombo and Kandy. Nevertheless, results are comparable with Nepal (31\%), Indonesia (35\%), and Singapore (26\%), lower than China (66\%), Japan (73\%), and Vietnam (47\%) but, higher than Afghanistan (10\%), Malaysia (17\%), and India (3-11\%) [20-24].

Second, BL infection was found to be more common among those who have an out-of-country travel history. This suggests that the infection might have occurred while being out-of-country. The reported BL prevalence of the countries visited by those who had BL infection were Singapore (26\%), India (3-11\%), Saudi Arabia (4.5\%), and Malaysia (17\%) $[20,21]$. Middle-East Asia, being a region that provides job opportunities as labourers, bears nearly $90 \%$ of Sri Lankan labour migrants out of 212,162 persons in 2017. Around $9.2 \%$ of the total labour migrants were from Kandy district, and it was the third highest district representative [25]. The first documented case of MDR-TB in a foreign-born migrant worker in Sri Lanka also had travelled to Kuwait and India [26]. In addition to workforce, Saudi Arabia is also visited for pilgrimage as was seen in our study. Apart from MiddleEast, Asian countries including Japan, Korea, and Malaysia have become the new labour migrant destination countries for people from developing countries. Moreover, labour migrants from South East Asia are prominently seen in construction projects in developing countries like Sri Lanka 
Beijing Multiplex PCR amplification steps*

PCR was carried out in a $25 \mu \mathrm{l}$ reaction mixture, containing $75 \mathrm{ng}$ of DNA, $0.33 \mathrm{mM}$ of each dNTP, $0.33 \mu \mathrm{M}$ of each Fw ( $5^{\prime}$ GTCACTGAACGTGGCCGGCTC3 ${ }^{\prime}$ ) and R1 (5'TCGGTCACCGTTTTTGTAGGTGACCGTC3') primers, $0.13 \mu \mathrm{M}$ of R2 (5'AGCAACCTCGCAATCTGACC3') primer, 1xPCR buffer, $2.25 \mathrm{mM} \mathrm{MgCl}_{2}$, and 0.8 units of Taq-DNA polymerase (Promega Corporation, Madison, Wisconsin, USA). Thermocycle program was set at initial denaturation at $95^{\circ} \mathrm{C}$ for 1 min, followed by 35 cycles of denaturation at $95^{\circ} \mathrm{C}$ for $10 \mathrm{~s}$, annealing at $66^{\circ} \mathrm{C}$ for $30 \mathrm{~s}$, elongation at $72^{\circ} \mathrm{C}$ for $30 \mathrm{~s}$, and final extension at $72^{\circ} \mathrm{C}$ for $3 \mathrm{~min}$. Conventional PCR amplification steps ${ }^{\S}$

PCR was carried out in a $25 \mu \mathrm{l}$ reaction mixture, containing $75 \mathrm{ng}$ of DNA, $0.4 \mathrm{mM}$ of each dNTP, $0.4 \mu \mathrm{M}$ of each Pt8

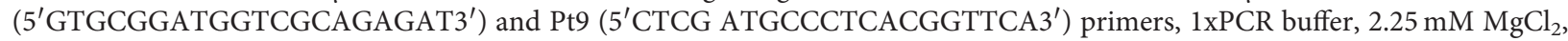
and 1 unit of Taq-DNA polymerase (Promega Corporation, Madison, Wisconsin, USA). Thermocycle program was set at initial denaturation at $94^{\circ} \mathrm{C}$ for $1 \mathrm{~min}$, followed by 45 cycles of denaturation at $95^{\circ} \mathrm{C}$ for $60 \mathrm{~s}$, annealing at $65^{\circ} \mathrm{C}$ for $60 \mathrm{~s}$, elongation at $72^{\circ} \mathrm{C}$ for $60 \mathrm{~s}$, and final extension at $72^{\circ} \mathrm{C}$ for $3 \mathrm{~min}$.

* Reference: C. Nakajima, A. Tamaru, Z. Rahim, et al., "Simple multiplex PCR assay for identification of Beijing family Mycobacterium tuberculosis isolates with a lineage-specific mutation in Rv0679c," Journal of Clinical Microbiology, vol. 51, no. 7, pp. 2025-2032, 2013.

${ }^{\S}$ Reference: D. Rhienthong, A. M. Miranda, N. Udomsantisuk, et al., “A more reliable PCR for detection of mycobacterium tuberculosis in clinical samples,” Journal of Clinical Microbiology, vol. 32, no. 3, pp. 672-678, 1994.

Box 1: PCR amplification steps.

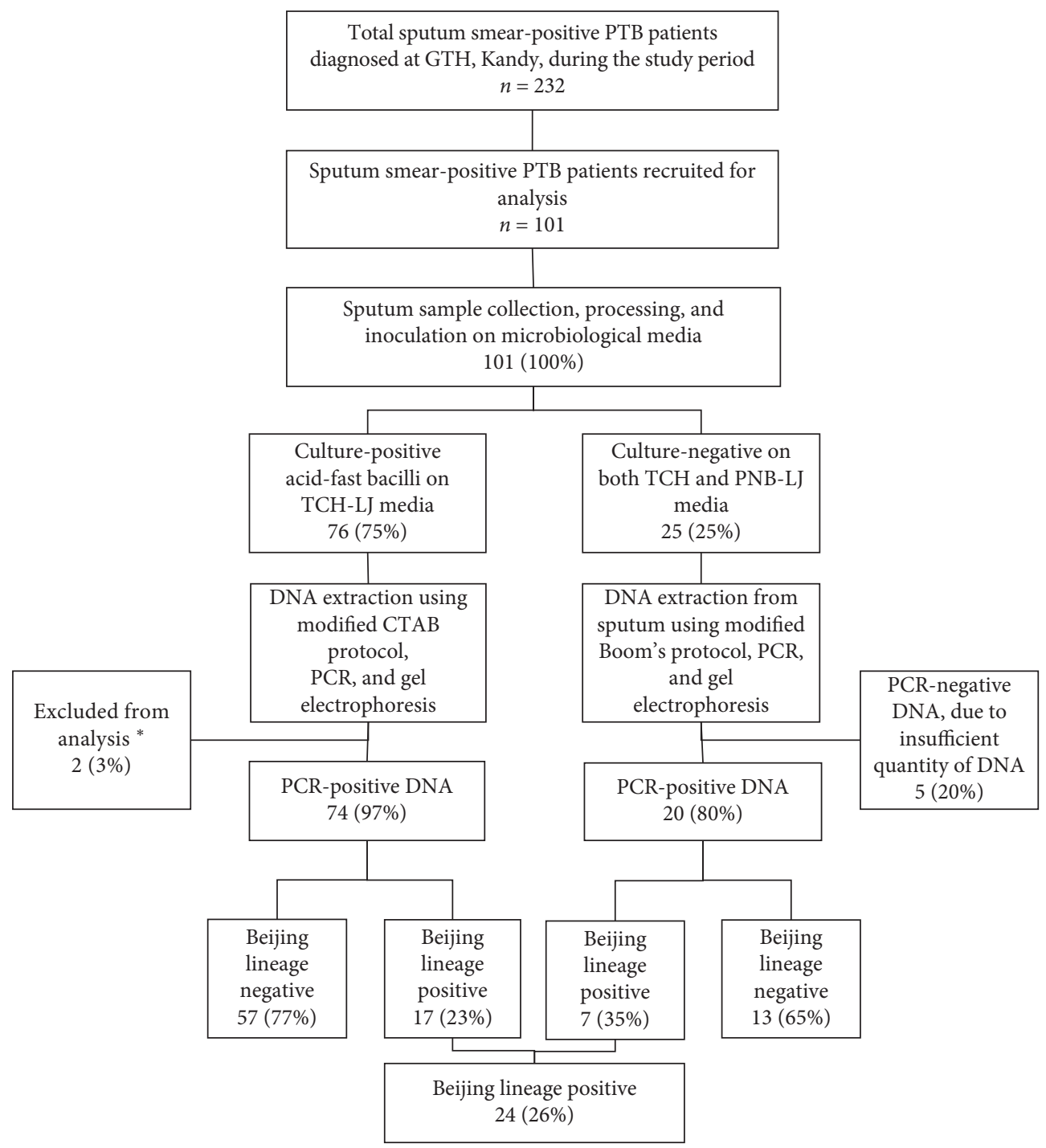

FIGURE 2: Prevalence of Beijing lineage strains among sputum smear-positive pulmonary tuberculosis (PTB) patients diagnosed in a tertiary care hospital in Kandy, Sri Lanka, during February 2018-July 2019. PCR-negative DNA, due to insufficient quantity of DNA. PTB: pulmonary tuberculosis, DNA: deoxyribonucleic acid, CTAB; cetyl trimethylammonium bromide, PCR: polymerase chain reaction, LJ: Lowenstein-Jensen media, TCH: thiophene-2-carboxylic acid hydrazide, PNB: para-nitrobenzoic acid. *Beijing/non-Beijing status could not be ascertained as they did not produce any band in Beijing multiplex PCR. However, they were confirmed as MTB upon conventional PCR. 


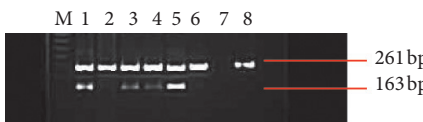

(a)

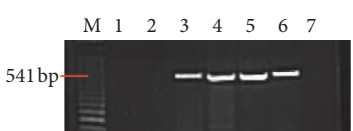

(b)

FIgURe 3: Agarose gel profiles displaying the PCR products of Beijing multiplex PCR and conventional PCR. (a) Agarose gel profile displaying the PCR products of Beijing multiplex PCR (M; 50 bp DNA marker; lanes 1, Beijing lineage positive control (a confirmed Beijing strain); 2-6, amplicons from culture isolates; 7, negative control (water); 8, non-Beijing control (the standard Mycobacterium tuberculosis strain H37Rv)). (b) Agarose gel profile displaying the PCR products of Beijing multiplex PCR and conventional PCR for the two culturepositive isolates in which the Beijing/non-Beijing status could not be ascertained (M; 50 bp DNA ladder; lanes 1, Beijing multiplex PCR product of culture isolate (a); 2, Beijing multiplex PCR product of culture isolate (b); 3 and 4, positive controls (the standard Mycobacterium tuberculosis strain H37Rv); 5, conventional PCR product of culture isolate (a); 6, conventional PCR product of culture isolate (b); 7, negative control (water)).

TABLE 1: Demographical, socioeconomic, and behavioural factors associated with Beijing lineage infection among TB patients diagnosed in a tertiary care hospital in Kandy, Sri Lanka, during February 2018-July 2019.

\begin{tabular}{|c|c|c|c|c|}
\hline \multirow{3}{*}{ Variable } & \multirow{3}{*}{$\begin{array}{c}\text { Total } \\
\quad N \\
94\end{array}$} & \multicolumn{2}{|c|}{$\begin{array}{l}\text { TB patients with Beijing } \\
\text { lineage strains }\end{array}$} & \multirow{3}{*}{ PR (95\% C.I.) } \\
\hline & & $n$ & $(\%)^{*}$ & \\
\hline & & 24 & $(26)$ & \\
\hline \multicolumn{5}{|l|}{ Age groups (years) } \\
\hline $15-34$ & 27 & 10 & $(37)$ & Reference \\
\hline $35-64$ & 58 & 13 & $(22)$ & $0.61(0.30-1.20)$ \\
\hline$\geq 65$ & 9 & 1 & $(11)$ & $0.30(0.04-2.03)$ \\
\hline \multicolumn{5}{|l|}{ Gender } \\
\hline Male & 62 & 15 & $(24)$ & $0.86(0.42-1.75)$ \\
\hline Female & 32 & 9 & $(28)$ & Reference \\
\hline \multicolumn{5}{|l|}{ Type of residency } \\
\hline Own house & 92 & 23 & $(25)$ & Reference \\
\hline Not own house & 2 & 1 & $(50)$ & $2.00(0.48-8.36)$ \\
\hline \multicolumn{5}{|c|}{ Out-of-country travel history } \\
\hline Not travelled & 81 & 17 & $(21)$ & Reference \\
\hline Travelled & 13 & 7 & $(54)$ & $2.57(1.33-4.95)$ \\
\hline \multicolumn{5}{|l|}{ Level of education } \\
\hline Up to primary & 13 & 2 & $(15)$ & Reference \\
\hline Secondary & 59 & 13 & $(22)$ & $1.43(0.37-5.59)$ \\
\hline High-school/university & 22 & 9 & $(41)$ & $2.66(0.68-10.47)$ \\
\hline \multicolumn{5}{|l|}{ Occupation } \\
\hline Professional & 20 & 4 & $(20)$ & $0.74(0.25-2.19)$ \\
\hline Labourer & 34 & 7 & $(21)$ & $0.76(0.31-1.91)$ \\
\hline Business & 14 & 6 & $(43)$ & $1.59(0.66-3.82)$ \\
\hline Not employed & 26 & 7 & (27) & Reference \\
\hline \multicolumn{5}{|l|}{ Monthly income (LKR) } \\
\hline No income & 27 & 8 & $(30)$ & $1.85(0.64-5.40)$ \\
\hline$\leq 10,000$ & 25 & 4 & $(16)$ & Reference \\
\hline$>10000$ & 42 & 12 & $(29)$ & $1.79(0.65-4.94)$ \\
\hline \multicolumn{5}{|l|}{ Use of alcohol } \\
\hline Yes & 45 & 11 & $(24)$ & $0.92(0.46-1.84)$ \\
\hline No & 49 & 13 & $(27)$ & Reference \\
\hline \multicolumn{5}{|l|}{ Smoking } \\
\hline Yes & 38 & 10 & $(26)$ & $1.05(0.52-2.12)$ \\
\hline No & 56 & 14 & (38) & Reference \\
\hline
\end{tabular}

${ }^{*}$ Row percentages. $\mathrm{PR}=$ prevalence ratio, C.I. = confidence interval, LKR = Sri Lankan rupees. Level of education: up to primary: grades 1-5, secondary: grades 6-11 (up to ordinary level examination), and high-school: grades 12-13 (up to advanced level examination). Occupation: labourer includes industry and estate labourers. Professional includes skilled workers in the following categories: government officers, hospital staff, tourist guidance, hotel management etc. 
TABLE 2: Out-of-country travel information of TB patients diagnosed in a tertiary care hospital in Kandy, Sri Lanka, between February 2018 and March 2019 disaggregated by their Beijing lineage strain status.

\begin{tabular}{lccc}
\hline $\begin{array}{l}\text { Out-of-country } \\
\text { travel history }\end{array}$ & $\begin{array}{c}\text { TB patients } \\
\text { infected with } \\
\text { Beijing lineage }(n)\end{array}$ & $\begin{array}{c}\text { TB patients } \\
\text { infected with non- } \\
\text { Beijing lineage }(n)\end{array}$ & $\begin{array}{c}P \\
\text { value }\end{array}$ \\
\hline $\begin{array}{l}\text { Travelled } \\
\text { Travelled to one }\end{array}$ & 7 & 6 & 0.0117 \\
country only & 6 & 4 & \\
Travelled to two & 1 & 2 & \\
countries & & & \\
\hline Country travelled & & 1 & \\
Dubai & 0 & 1 & \\
Germany & 0 & 1 & \\
Jordan & 0 & 0 & \\
Kuwait & 3 & 1 & \\
Malaysia & 1 & 2 & \\
Saudi Arabia & 2 & 0 & \\
Singapore & 1 & 0 & \\
India & 1 & 1 & \\
Japan & 0 & 1 & \\
Maldives & 0 & & \\
\hline
\end{tabular}

Duration of visit abroad

Less than one

year

$1-5$ years

$6-10$ years

$10-15$ years

$16-20$ years

21-25 years

Not recorded

Purpose of travel

Labour migrant

Pilgrimage

Tourism

Other

2
3
0
1
1
0
0

$P$ value $<0.05$.

[25]. In this context, the inflow of virulent MTB strains through migration should not be underestimated. However, significant correlation of duration of their stay abroad and purpose of travel was not observed, and further testing is required to confirm the strain origin.

Third, a significantly larger proportion of patients with BL strains had high sputum smear grades. Sputum grading is a direct indicator of bacillary load, and higher grades are associated with higher bacillary load, thereby increasing risk of $\mathrm{TB}$ transmission [27]. Some studies have reported higher bacillary load among BL strains, whereas others have reported similar bacillary loads $[28,29]$. This perhaps explains the reasons for higher TB transmission linked to BL.

Fourth, the BL infection was more common among young people. This is consistent with studies done in Vietnam, Hong Kong, and Bangladesh [30, 31]. TB among youth represents recent transmission when compared to adults in whom reactivation of previous infection is more common [4]. Thus, we hypothesize that non-Beijing strains were more common earlier, and it may be getting replaced
TABLE 3: Clinical presentation among pulmonary tuberculosis patients in a tertiary care hospital in Kandy, Sri Lanka (February 2018-July 2019).

\begin{tabular}{|c|c|c|c|c|c|}
\hline & \multicolumn{2}{|c|}{$\begin{array}{l}\text { TB patients } \\
\text { infected } \\
\text { with Beijing } \\
\text { lineage }\end{array}$} & \multicolumn{2}{|c|}{$\begin{array}{l}\text { TB patients } \\
\text { infected } \\
\text { with non- } \\
\text { Beijing } \\
\text { lineage }\end{array}$} & \multirow[t]{2}{*}{ Total } \\
\hline & $n$ & $(\%) \S$ & $n$ & $(\%) \S$ & \\
\hline Total & 24 & & 70 & & \\
\hline \multicolumn{6}{|l|}{ Sputum grade } \\
\hline Low grade (scanty/1+) & 8 & $(33)$ & 40 & $(57)$ & 48 \\
\hline High grade $(2+/ 3+)$ & 16 & $(67)$ & 30 & $(43)$ & 46 \\
\hline \multicolumn{6}{|l|}{ Symptoms } \\
\hline Cough & 23 & $(25)$ & 69 & $(75)$ & 92 \\
\hline Fever & 14 & $(58)$ & 33 & (47) & 47 \\
\hline Headache & 0 & $(0)$ & 11 & (17) & 11 \\
\hline Haemoptysis & 4 & (17) & 16 & (23) & 20 \\
\hline Loss of weight & 13 & (54) & 38 & $(54)$ & 51 \\
\hline Body pain & 2 & (11) & 3 & (6) & 5 \\
\hline \multicolumn{6}{|l|}{ Type of TB patient } \\
\hline New & 24 & $(100)$ & 67 & $(96)$ & 91 \\
\hline Relapse & 0 & $(0)$ & 3 & (4) & 3 \\
\hline \multicolumn{6}{|l|}{ Presence of comorbidities } \\
\hline Diabetes mellitus & 7 & (29) & 16 & $(23)$ & 23 \\
\hline Asthma & 0 & $(0)$ & 4 & (6) & 4 \\
\hline
\end{tabular}

TB: tuberculosis. $P$ value $<0.05 . \$=$ column percentages. Type of TB patient: new: never been treated for TB or have taken anti-TB drugs for less than 1 month; relapse: previously treated for TB were declared cured or treatment completed at the end of their most recent course of treatment and are now diagnosed with a recurrent episode of TB (either a true relapse or a new episode of TB caused by reinfection) (Reference: WHO, Definitions and Reporting Framework for Tuberculosis-2013 Revision, World Health Organization, Geneva, Switzerland, 2013.).

with Beijing strains off late. Whether our hypothesis is true or not needs to be assessed in future studies.

Lastly, the clinical features and the TB treatment outcomes were similar in all patients. This is in contrast to the previous knowledge from a meta-analysis which had concluded that BL strains are associated with unfavourable treatment outcomes [29, 32].

The study had a few limitations. For two MTB isolates, we could not ascertain Beijing/non-Beijing status, which could perhaps be due to deletion/mutation in the Rv0627c gene. The other limitation was the small sample size because of which the 95\% CIs for assessing the differences in the patient characteristics with and without BL strains are wide and imprecise. Therefore, we cannot conclude with statistical certainty whether there were or there were no differences in the patient characteristics. Given this scenario, we strongly feel that it is important to take note of the magnitude and direction of central values of the association measures, which we believe would not have changed if the study has been conducted with larger sample size. We recruited a subsample of patients who nearly constituted half of the PTB patients diagnosed in Kandy during the study period. Therefore, the findings are generalizable to all PTB patients in Kandy. Moreover, we ensured data quality by prospective data collection which adds much strength to our findings. 
TABLE 4: Comparison of treatment outcome of $64 \mathrm{~TB}$ patients diagnosed in a tertiary care hospital in Kandy, Sri Lanka, between February 2018 and March 2019 disaggregated by their Beijing lineage strain status.

\begin{tabular}{|c|c|c|c|c|c|}
\hline \multirow[t]{2}{*}{ Treatment outcome* } & \multicolumn{2}{|c|}{$\begin{array}{l}\text { TB patients infected with } \\
\text { Beijing lineage }\end{array}$} & \multicolumn{2}{|c|}{$\begin{array}{l}\text { TB patients infected with } \\
\text { non-Beijing lineage }\end{array}$} & \multirow[t]{2}{*}{$P$ value } \\
\hline & $n$ & $(\%) \S$ & $n$ & $(\%) \S$ & \\
\hline $\begin{array}{l}\text { Total } \\
\text { Favorable }\end{array}$ & 12 & & 52 & & \\
\hline Cured & 10 & $(83)$ & 42 & $(81)$ & 0.8375 \\
\hline Unfavorable & 2 & (17) & 10 & (19) & \\
\hline Died & 0 & (0) & 3 & (6) & \\
\hline Not evaluated & 2 & (17) & 7 & (13) & \\
\hline
\end{tabular}

TB: tuberculosis. $\$=$ column percentage. $P$ value $<0.05$. Note. The table gives data only of the patients whose treatment outcome information were available by September 2019 ( $n=64)$. * Reference: WHO, Definitions and Reporting Framework for Tuberculosis-2013 Revision, World Health Organization, Geneva, Switzerland, 2013.

\section{Conclusions}

In conclusion, the BL prevalence in Kandy, Sri Lanka, was high accounting $26 \%$ of PTB patients. The value is much closer to the percentages reported from South East Asia, the hub of BL MTB strains. BL-infected patients appear to be young, likely to contain higher sputum bacillary load, and a majority have an out-of-country travel history. We assume that we would expect similar observations even in other underexplored countries, and these features have the potential to alter the TB epidemiology as a whole. Findings further emphasize the importance of policies and practices to be followed in terms of immigration/emigration not only in Sri Lanka but also globally. Hence, it is important to monitor the trends in the prevalence of Beijing strain and associated risk factors globally and take necessary actions to combat the issue.

\section{Data Availability}

Data generated during the study will be available from the corresponding author upon reasonable request.

\section{Conflicts of Interest}

The authors declare that there are no conflicts of interest regarding the publication of this article.

\section{Acknowledgments}

The authors would like to convey their acknowledgement to the staff of General Teaching Hospital, Kandy, Sri Lanka, and all the patients for their support in conducting the research. This research was conducted through the Structured Operational Research and Training Initiative (SORT IT), a global partnership led by the Special Program for Research and Training in Tropical Diseases at the World Health Organization (WHO/TDR). The model is based on a course developed jointly by the International Union against Tuberculosis and Lung Disease (The Union) and Medécins sans Frontières (MSF/Doctors Without Borders). The specific SORT IT program which resulted in this publication was jointly developed and implemented by The Union SouthEast Asia Office, New Delhi, India; the Centre for
Operational Research, The Union, Paris, France; The Union, Mandalay, Myanmar; The Union, Harare, Zimbabwe; MSF Luxembourg Operational Research (LuxOR); MSF Operational Center Brussels (MSF OCB); Jawaharlal Institute of Postgraduate Medical Education and Research (JIPMER), Puducherry, India; Post Graduate Institute of Medical Education and Research (PGIMER), Chandigarh, India; All India Institute of Medical Sciences (AIIMS), New Delhi, India; ICMR- National institute of Epidemiology, Chennai, India; Society for Education Welfare and Action (SEWA) -Rural, Jhagadia, India; Common Management Unit (AIDS, TB \& Malaria), Ministry of National Health Services, Regulations and Coordination, Islamabad, Pakistan; and Kidu Mobile Medical Unit, His Majesty's People's Project and Jigme Dorji Wangchuck National Referral Hospital, Thimphu, Bhutan. This research was funded by National Science Foundation, Sri Lanka (NSF/PSF/ICRP/2017/HS/01) and National Institute of Fundamental Studies, Kandy, Sri Lanka. The training programme and the open access publication costs were funded by the Department for International Development (DFID) and UK and La Fondation Veuve Emile Metz-Tesch (Luxembourg). The funders had no role in study design, data collection and analysis, decision to publish, or preparation of the manuscript.

\section{Supplementary Materials}

Table S1: treatment outcome definitions for TB patients (excluding patients treated for RR-TB or MDR-TB). (Supplementary Materials)

\section{References}

[1] S. A. Yimer, G. Norheim, A. Namouchi et al., "Mycobacterium tuberculosis lineage 7 strains are associated with prolonged patient delay in seeking treatment for pulmonary tuberculosis in Amhara region, Ethiopia," Journal of Clinical Microbiology, vol. 53, no. 4, pp. 1301-1309, 2015.

[2] J. R. Glynn, J. Whiteley, P. J. Bifani, K. Kremer, and D. van Soolingen, "Worldwide occurrence of beijing/W strains of mycobacterium tuberculosis: a systematic review," Emerging Infectious Diseases, vol. 8, no. 8, pp. 843-849, 2002.

[3] K. Kremer, J. R. Glynn, T. Lillebaek et al., "Definition of the beijing/W lineage of mycobacterium tuberculosis on the basis 
of genetic markers," Journal of Clinical Microbiology, vol. 42, no. 9, pp. 4040-4049, 2004.

[4] C. Yang, T. Luo, G. Sun et al., "Mycobacterium tuberculosis Beijing strains favor transmission but not drug resistance in China," Clinical Infectious Diseases, vol. 55, no. 9, pp. 1179-1187, 2012.

[5] J. A. Caminero, M. J. Pena, M. I. Campos-Herrero et al., "Epidemiological evidence of the spread of a mycobacterium tuberculosis strain of the beijing genotype on gran Canaria Island," American Journal of Respiratory and Critical Care Medicine, vol. 164, no. 7, pp. 1165-1170, 2001.

[6] S. Hoffner, L. Sahebi, K. Ansarin, S. Sabour, and P. Mohajeri, "Mycobacterium tuberculosis of the beijing genotype in Iran and the world health organization eastern mediterranean region: a meta-analysis," Microbial Drug Resistance, vol. 24, no. 6, pp. 693-698, 2018.

[7] World Health Organization (WHO), Global Tuberculosis Report, World Health Organization (WHO), Geneva, Switzerland, 2019.

[8] M. Karmakar, J. M. Trauer, D. B. Ascher, and J. T. Denholm, "Hyper transmission of beijing lineage mycobacterium tuberculosis: systematic review and meta-analysis," Journal of Infection, vol. 79, no. 6, 2019.

[9] T. Lillebaek, Å. B. Andersen, A. Dirksen, J. R. Glynn, and K. Kremer, "Mycobacterium tuberculosis Beijing genotype1," Emerging Infectious Diseases, vol. 9, no. 12, pp. 1553-1557, 2003.

[10] U. S. Rajapaksa, T. C. Victor, A. J. Perera, R. M. Warren, and S. M. P. Senevirathne, "Molecular diversity of mycobacterium tuberculosis isolates from patients with pulmonary tuberculosis in Sri Lanka," Transactions of the Royal Society of Tropical Medicine and Hygiene, vol. 102, no. 10, pp. 997-1002, 2008.

[11] C. Mendis, V. Thevanesam, A. Kumara et al., "Insight into genetic diversity of mycobacterium tuberculosis in Kandy, Sri Lanka reveals predominance of the Euro-American lineage," International Journal of Infectious Diseases, vol. 87, pp. 84-91, 2019.

[12] World Health Organization, Tuberculosis Country Profile Sri Lanka, World Health Organization (WHO), Geneva, Switzerland, 2017.

[13] A. P. Wickramasinghe, D. G. G. P. Karunaratne, and R. Sivakanesan, "PM10-bound polycyclic aromatic hydrocarbons: concentrations, source characterization and estimating their risk in urban, suburban and rural areas in Kandy, Sri Lanka," Atmospheric Environment, vol. 45, no. 16, pp. 2642-2650, 2011.

[14] World Health Organization (WHO), Guidelines for Treatment of Drug-Susceptible Tuberculosis and Patient Care, World Health Organization (WHO), Geneva, Switzerland, 2017.

[15] K. Tripathi, P. C. Tripathi, S. Nema et al., "Modified petroff's method: an excellent simplified decontamination technique in comparison with petroff s method," International Journal of Recent Trends in Science and Technology, vol. 10, pp. 461464, 2014.

[16] R. Boom, C. J. A. Sol, M. M. M. salimans, C. L. jansen, and P. M. E. Wertheim-van Dillen JVDN, "Rapid and simple method for purificaion of nucleic acids," Journal of Clinical Microbiology, vol. 28, no. 3, pp. 495-503, 1990.

[17] W. Somerville, L. Thibert, K. Schwartzman, and M. A. Behr, "Extraction of mycobacterium tuberculosis DNA: a question of containment," Journal of Clinical Microbiology, vol. 43, no. 6, pp. 2996-2997, 2005.

[18] C. Nakajima, A. Tamaru, Z. Rahim et al., "Simple multiplex PCR assay for identification of Beijing family mycobacterium tuberculosis isolates with a lineage-specific mutation in Rv0679c," Journal of Clinical Microbiology, vol. 51, no. 7, pp. 2025-2032, 2013.

[19] D. Rhienthong, A. M. Miranda, N. Udomsantisuk et al., "A more reliable pcr for detection of mycobacterium tuberculosis in clinical samples," Journal of Clinical Microbiology, vol. 32, no. 3, pp. 672-678, 1994.

[20] A. Gupta, S. Kulkarni, and A. S. Rastogi Nalin, "A study of mycobacterium tuberculosis genotypic diversity and drug resistance mutations in Varansi, north India," Indian Journal of Medical Research, vol. 139, pp. 892-902, 2014.

[21] L. Zhao, M. Li, H. Liu et al., "Beijing genotype of mycobacterium tuberculosis is less associated with drug resistance in south China," International Journal of Antimicrobial Agents, vol. 54, no. 6, pp. 766-770, 2019.

[22] J. R. Glynn, K. Kremer, M. W. Borgdorff et al., "Beijing/W genotype mycobacterium tuberculosis and drug resistance," Emerging Infectious Diseases, vol. 12, pp. 736-743, 2006.

[23] B. Malla, D. Stucki, S. Borrell et al., "First insights into the phylogenetic diversity of mycobacterium tuberculosis in Nepal," PLoS One, vol. 7, pp. 1-8, 2012.

[24] Y.-Y. Chen, J.-R. Chang, W.-F. Huang et al., "Genetic diversity of the mycobacterium tuberculosis east African-Indian family in three tropical Asian countries," Journal of Microbiology, Immunology and Infection, vol. 50, no. 6, pp. 886-892, 2017.

[25] Sri Lanka Bureau of Foreign Employment, Annual Statistical Report of Foreign Employment 2017, Sri Lanka Bureau of Foreign Employment, Battaramulla, Sri Lanka, 2017.

[26] K. Wickramage, S. Samaraweera, S. Peiris, J. Elvitigala, and D. Patabendige, "Multi-drug resistant tuberculosis in a foreign resident visa holder and implications of a growing inbound migrant flow to Sri Lanka," Sri Lankan Journal of Infectious Diseases, vol. 3, no. 2, p. 31, 2013.

[27] S. Diktanas, E. Vasiliauskiene, K. Polubenko et al., "Factors associated with persistent sputum positivity at the end of the second month of tuberculosis treatment in Lithuania," Tuberculosis and Respiratory Diseases, vol. 81, no. 3, pp. 233-240, 2018.

[28] D. Langlois-Klassen, A. Senthilselvan, L. Chui et al., "Transmission of mycobacterium tuberculosis Beijing strains, Alberta, Canada, 1991-2007," Emerging Infectious Diseases, vol. 19, no. 5, pp. 701-711, 2013.

[29] I. Parwati, B. Alisjahbana, L. Apriani et al., "Mycobacterium tuberculosis Beijing genotype is an independent risk factor for tuberculosis treatment failure in Indonesia," The Journal of Infectious Diseases, vol. 201, no. 4, pp. 553-557, 2010.

[30] H. Erie, H. Kaboosi, N. Javid et al., "The high prevalence of mycobacterium tuberculosis Beijing strain at an early age and extra-pulmonary tuberculosis cases," Iranian Journal of Microbiology, vol. 9, pp. 312-317, 2017.

[31] D. D. Anh, M. W. Borgdorff, L. N. Van et al., "Mycobacterium tuberculosis Beijing genotype emerging in Vietnam," Emerging Infectious Diseases, vol. 6, no. 3, pp. 302-305, 2000.

[32] Q. Liu, D. Wang, L. Martinez et al., "Mycobacterium tuberculosis Beijing genotype strains and unfavourable treatment outcomes: a systematic review and meta-analysis," Clinical Microbiology and Infection, vol. 26, no. 5, pp. 180-188, 2019. 